\title{
Partnership for the Revitalization of National Wind Tunnel Force Measurement Capability
}

\author{
Ray D. Rhew ${ }^{1}$ \\ NASA Langley Research Center, Hampton, VA \\ Marcus L. Skelley ${ }^{2}$ \\ U.S. Air Force, Arnold Engineering Development Center, Arnold AFB, TN \\ Mark R. Woike ${ }^{3}$ \\ NASA Glenn Research Center, Cleveland, $\mathrm{OH}$ \\ Jon B. Bader ${ }^{4}$ \\ NASA Ames Research Center, Mountain View, CA \\ and \\ Timothy J. Marshall ${ }^{5}$ \\ NASA Aeronautics Test Program, LaRC, Hampton, VA
}

\begin{abstract}
Lack of funding and lack of focus on research over the past several years, coupled with force measurement capabilities being decentralized and distributed across the National Aeronautics and Space Administration (NASA) research centers, has resulted in a significant erosion of (1) capability and infrastructure to produce and calibrate force measurement systems; (2) NASA's working knowledge of those systems; and (3) the quantity of high-quality, full-capability force measurement systems available for use in aeronautics testing. Simultaneously, and at proportional rates, the capability of industry to design, manufacture, and calibrate these test instruments has been eroding primarily because of a lack of investment by the aeronautics community. Technical expertise in this technology area is a core competency in aeronautics testing; it is highly specialized and experience-based, and it represents a niche market for only a few small precision instrument shops in the United States.

With this backdrop, NASA's Aeronautics Test Program (ATP) chartered a team to examine the issues and risks associated with the problem, focusing specifically on straingage balances. The team partnered with the U.S. Air Force's Arnold Engineering Development Center (AEDC) to exploit their combined capabilities and take a national level government view of the problem. This paper describes the team's approach, its findings, and its recommendations, and the current status for revitalizing the government's balance capability with respect to designing, fabricating, calibrating, and using the instruments.
\end{abstract}

${ }^{1}$ Aerospace Technologist, NASA Langley Research Center, Hampton, VA

${ }^{2}$ Senior Project Manager, 716th Test Squadron (Flight Systems), Arnold Engineering Development Center, Arnold AFB TN, AIAA Senior Member

${ }^{3}$ Electronics Engineer, NASA Glenn Research Center, Cleveland, OH

${ }^{4}$ Wind Tunnel Systems Branch Chief, NASA Ames Research Center, Mountain View, CA

${ }^{5}$ Deputy Director, Aeronautics Test Program, NASA Langley Research Center, Hampton, VA 


\section{Nomenclature}

$\begin{array}{ll}\text { AEDC } & =\text { Arnold Engineering Development Center } \\ \text { ARC } & =\text { Ames Research Center } \\ \text { ARMD } & =\text { Aeronautics Research Mission Directorate } \\ \text { ATP } & =\text { Aeronautics Test Program } \\ \text { BTWT } & =\text { Boeing Transonic Wind Tunnel } \\ \text { DoD } & =\text { Department of Defense } \\ \text { FTE } & =\text { Full-time equivalent } \\ \text { GRC } & =\text { Glenn Research Center } \\ \text { LaRC } & =\text { Langley Research Center } \\ \text { NASA } & =\text { National Aeronautics and Space Administration } \\ \text { NFMTC } & =\text { National Force Measurement Technology Capability } \\ \text { PA\&E } & =\text { Program analysis and evaluation } \\ \text { POC } & =\text { Point of contact } \\ \text { R\&D } & =\text { Research and development } \\ \text { SCAP } & =\text { Shared Capability Asset Program }\end{array}$

\section{Introduction}

$\mathrm{T}$ HE workload at each of NASA's individual research centers and wind tunnels has not been sufficient to maintain critical skills in the area of force measurement. Without intervention the following could be expected to occur: (1) NASA's capability to produce, calibrate, repair, and utilize these instruments in novel test arrangements will disappear altogether; (2) the number of useable strain-gage balances in NASA's inventory will be significantly reduced, which will severely impact NASA's ability to meet its future wind tunnel testing requirements, thus impacting all the NASA mission directorates through increased schedules and costs and reduced data quality; and (3) the risks of complete failure of in-service strain-gage balances will increase until a catastrophic event occurs. It has become obvious that strategic investments in infrastructure, technology development, and personnel are necessary to maintain this critical capability for the nation.

The Aeronautics Test Program (ATP) was created by NASA to preserve the capabilities of the largest, most versatile and comprehensive set of testing facilities in the United States. The portfolio of ATP facilities appears in Fig. 1. The goals of the ATP include increasing the probability of having the right capabilities in place at the right time, operating the necessary facilities in the most effective and efficient manner possible to foster those capabilities through a corporate management philosophy, and ensuring intelligent investment and divestment while sustaining core capabilities. The ATP attempts to achieve these goals by management initiatives such as integrated management of the facility portfolio, internal and external agreements, competitive pricing and rate structure, and user awareness events, as well as through investment activities for operations and maintenance support, test capability sustainment and test technology and facility research. The following is a comprehensive list of ATP objectives:

\begin{tabular}{|c|c|}
\hline $\begin{array}{l}\text { AMES RESEARCH CENTER } \\
\text { - } 11 \text {-ft Transonic Unitary Wind Tunnel } \\
\text { - } 9 x 7 \text { Supersonic Wind Tunnel } \\
\text { - } 12 \text {-ft Subsonic Pressure Wind Tunnel } \\
\text { DRYDEN FLIGHT RESEARCH CENTER } \\
\text { - Western Aeronautical Test Range } \\
\text { - Support and Test-Bed Aircraft } \\
\text { - Flight Loads Laboratory } \\
\text { - } \text { Flight Simulators } \\
\text { - Icing Research Tunnel } \\
\text { - } 10 x 10 \text { Supersonic Unitary Wind Tunnel } \\
\text { - } 8 x 6 \text { Transonic Wind Tunnel } \\
\text { - 9x15 Low Speed Wind Tunnel } \\
\text { - Propulsion Systems Lab } 3 \text { and } 4 \\
\text { - ECRL-2B } \\
\text { - Aero-Acoustic Propulsion Laboratory } \\
\text { - Hypersonic Test Facility }\end{array}$ & $\begin{array}{l}\text { LANGLEY RESEARCH CENTER } \\
\text { - } \quad \text { National Transonic Facility } \\
\text { - } 0.3-\mathrm{m} \text { Transonic Cryogenic Tunnel } \\
\text { - } 8 \text {-ft High Temperature Tunnel } \\
\text { - } 20 \text {-in. Mach } 6 \text { CF4 Tunnel } \\
\text { - } 31 \text {-in. Mach } 10 \text { Tunnel } \\
\text { - } 15 \text {-in. Mach } 6 \text { Tunnel } \\
\text { - } 20 \text {-in. Mach } 6 \text { Hypersonic Tunnel } \\
\text { - } 20 \text {-in. Supersonic Wind Tunnel } \\
\text { - } 22 \text {-in. Mach } 20 \text { Hypersonic Tunnel } \\
\text { - } 14 x 22 \text { Subsonic Wind Tunnel } \\
\text { - Transonic Dynamics Tunnel } \\
\text { - } \text { 4-ft Supersonic Unitary Wind Tunnel } \\
\text { - } 20 \text {-ft Vertical Spin Tunnel } \\
\text { - Low-Turbulence Pressure Tunnel } \\
\text { - Jet Exit Test Facility } \\
\text { - } 30 x 60 \text { Full-Scale Tunnel }\end{array}$ \\
\hline
\end{tabular}

Figure 1. Aeronautics test program facility portfolio. 
- Implement an integrated, consistent approach to the management of major wind tunnels/ground-test facilities and flight operations/test infrastructure.

- Accomplish efficient and effective usage of NASA's major wind tunnels/ground-test facilities and flight operations/test infrastructure and other resources to optimize user service and to meet national test requirements.

- Ensure stable, affordable, and market-based rates for ATP facilities. Market-based facility rates are those rates which are on parity with rates for facilities providing similar test capabilities operated by other U.S. Government agencies, U.S. industries, or foreign entities. These market-based rates will be reviewed at least annually to ensure parity.

- Maximize return on investments through facility modernization, technology development, and sound maintenance strategies.

- Provide a stable level of investment, including maintenance, revitalization, and required upgrades.

- Periodically identify and validate the set of facilities that the ARMD and/or SCAP will support.

- Develop a facility divestment/investment plan that supports current and/or long-term missions of NASA, DoD, and U.S. industry.

- Maintain and develop mutually beneficial testing partnerships between NASA, DoD, other Government agencies, and the U.S. commercial sector.

- Maintain a commitment to safety and mission success.

With that backdrop, the ATP evaluated core competencies within its portfolio of facilities and became increasingly concerned about the state of force measurement at NASA. Force measurement is a technology that is critical for wind tunnel testing and is a highly specialized, experience-based niche market for a few precision machine shops around the country. At NASA, lack of funding and decentralization had eroded the capability to not only produce, calibrate and repair balances, but even to use them in novel test arrangements. The number of usable balances in the inventory was on the decline along with safeguards against catastrophic failure. The aeronautics industry retained some in-house capability, but it seemed to be deteriorating as well.

So what is a balance? Strain-gage balances are specialized and highly complex force measurement instruments developed for wind tunnel applications. Reference 1 provides additional in-depth details on wind tunnel balances and their applications. Balances are used to measure the aerodynamic loads acting on the test article (model). Figure 2 shows a test article in a wind tunnel, a sketch showing the balance, and the loads the balance measures followed by a picture of a typical balance. Figure 3 provides additional examples of the types and sizes of balances used for wind tunnel experiments. By design, strain-gage balances operate at high stress levels which limit their useful life because of material fatigue limits. The mechanical failure of a strain-gage balance in a wind tunnel test

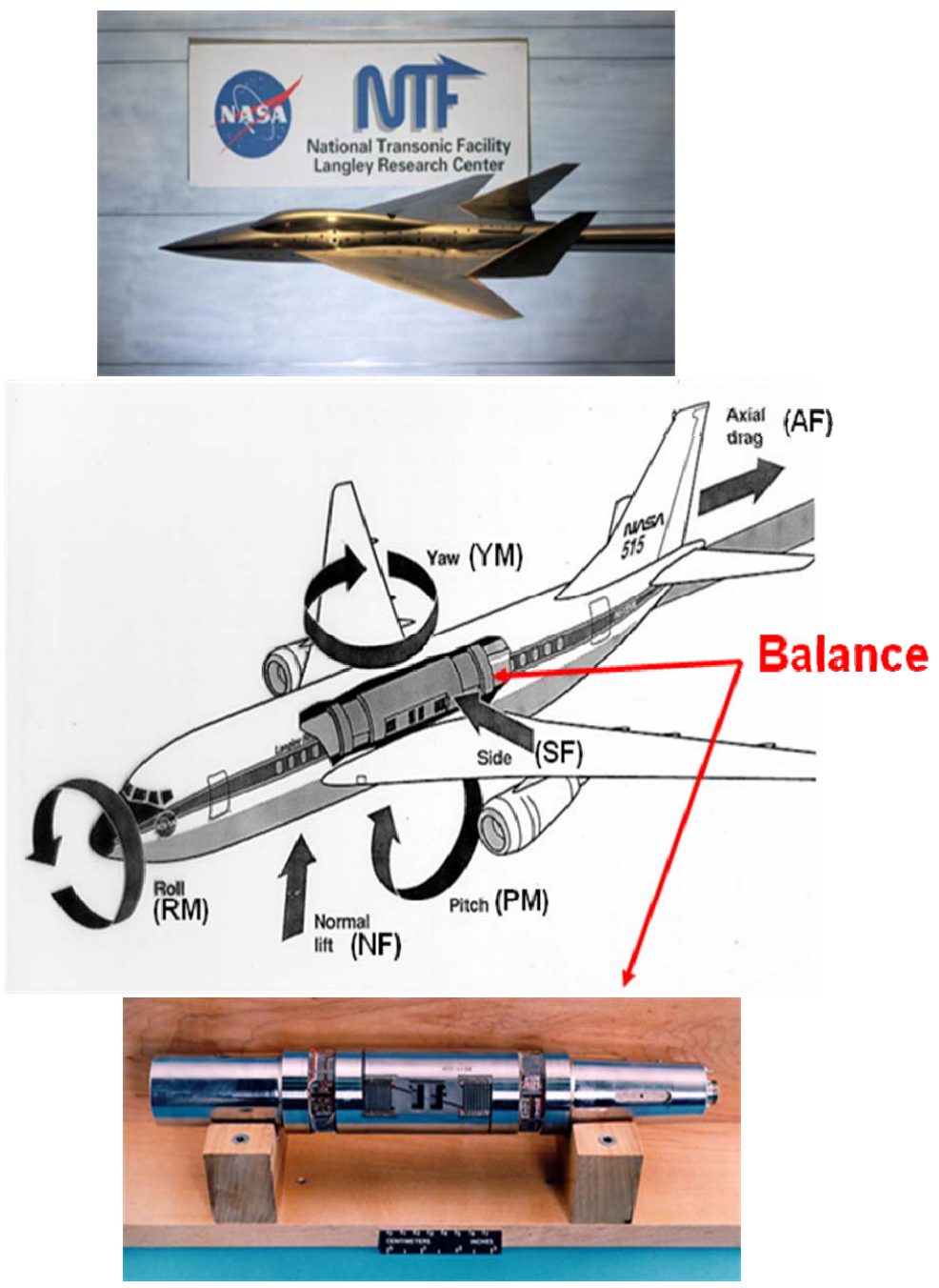

Figure 2. Balance uses. 
would likely be catastrophic, causing loss of the test article, significant damage to the wind tunnel, a significant period of unplanned facility down-time, and corresponding lost opportunity costs.

Internal balances have been used in wind tunnels since the early 1940s. They can be designed to measure from one to six components of the load, and measurement of all six components is necessary to completely define a total load. Total loads are a combination of the aerodynamic loads, model weight, and a portion of the weight of the balance itself. A balance measures the loads by using strain gages, arranged in a Wheatstone bridge, to measure the strain produced by the loads. A balance measuring six component loads (universally referred to as a sixcomponent balance) will have a total of six (or more) Wheatstone bridges.

As with all instrumentation, proper calibration is critical to ensure that a good measurement can be taken. A calibration setup for small balances is shown in Fig. 4. Once a balance is calibrated and placed inside a wind tunnel model, checkloads are performed with known weights to validate that the balance is reacting and measuring correctly. A checkloading procedure on a full-stack space shuttle wind tunnel model is shown in Fig. 5.

Accurate measurements of forces and moments experienced by a test article (aircraft, missile, munition, etc.) in a wind tunnel test, coupled with measurement of the test article's attitude (angle of attack, yaw, and roll) are the central base from which predictions of the overall system aerodynamic performance are derived.
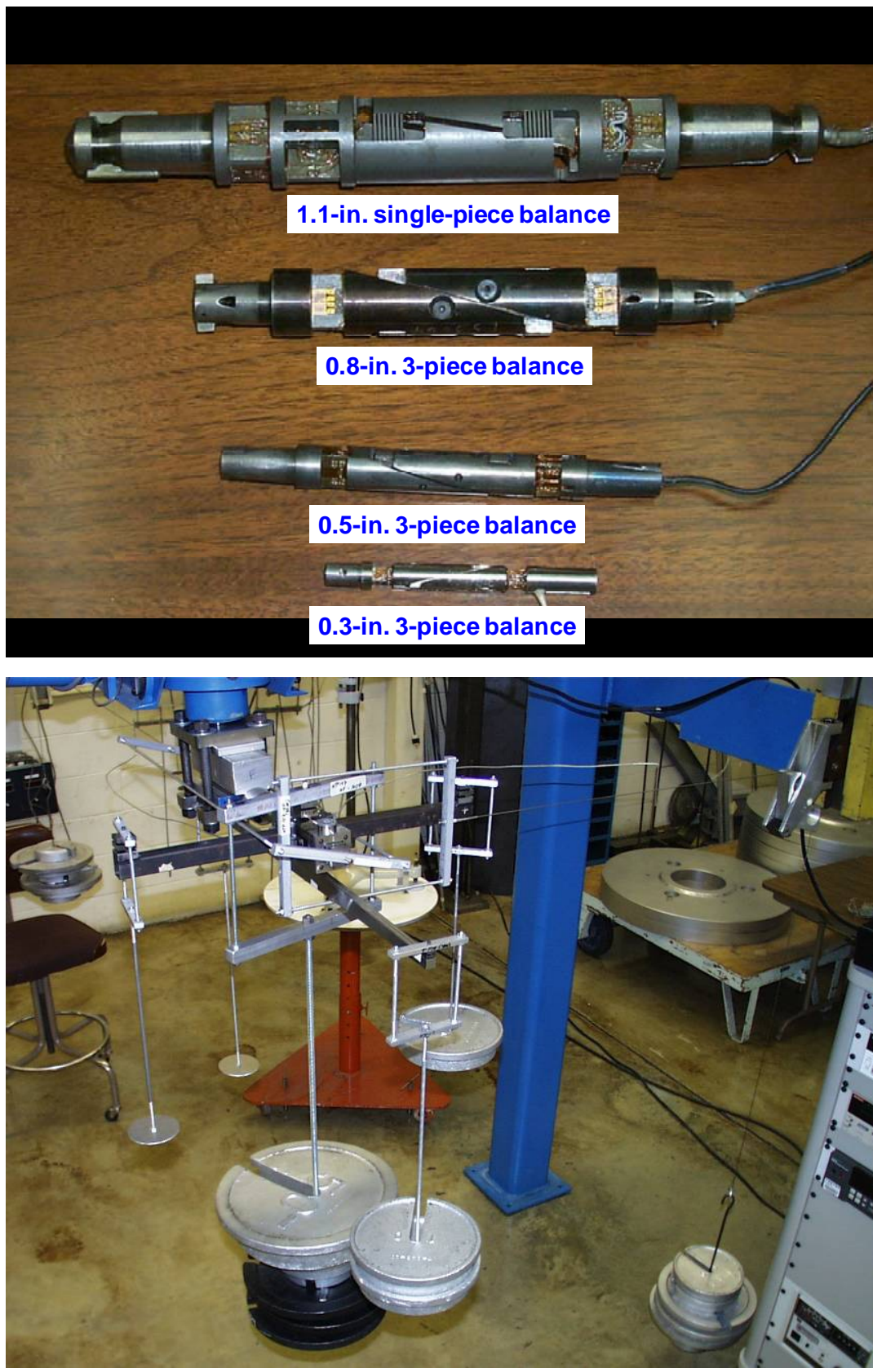

Figure 4. Balance calibration setup.

Figure 3. Example balances.

This can be true not only for an

aircraft itself, but also for measuring the loads on aircraft stores as well as supporting certification of weapons delivery from military aircraft. Inaccuracies in these measurements lead to increased risk of achieving performance goals and increased product development cycle time and acquisition cost. Consequently, for a wind tunnel it is vital to the mission that balances give state-of-the-art results in order to validate aircraft design performance.

Thus, the ATP has identified force measurement as one of the fundamental capabilities to achieve its charter. The ultimate goal for the team is to set the foundation for this capability by providing resources to establish a national force measurement technology group ready to support aeronautics test requirements for NASA, AEDC, and the U.S. with the initial emphasis on wind tunnel strain-gage balances. Once established, this capability would be utilized by the U.S. Government for all of its force measurement testing needs. 


\section{Team Charter and Approach}

A team was created to examine the current state of the force measurement capability at NASA and around the country, then formulate and implement a national strategy to revitalize this important capability. In partnership with the Air Force in order to exploit the combined capability of U.S. Government aeronautical testing centers, the team was assembled in December 2006 and consisted of representatives from each of the NASA Research Centers-Langley Research Center (LaRC), Ames Research Center (ARC), and Glenn Research Center (GRC)—along with a representative from the U.S. Air Force's Arnold Engineering and Development Center (AEDC). The team was chartered to verify ATP concerns, identify possible risks, and, if the concerns were confirmed, identify steps to restore and maintain technical competency, establish a recapitalization strategy, and implement a procurement strategy.

The team began with a series of meetings at each of the four centers and with technical interchanges to evaluate the state of affairs of force measurement at each location. This included a fairly extensive literature review of past balance studies and reports from a wide variety of authors and locations, as well as tours and briefings at each of the respective facilities. Consultations with procurement offices at both LaRC and AEDC were also done to evaluate procurement strategies for balance hardware buys as well as service contracts. Once a baseline was set

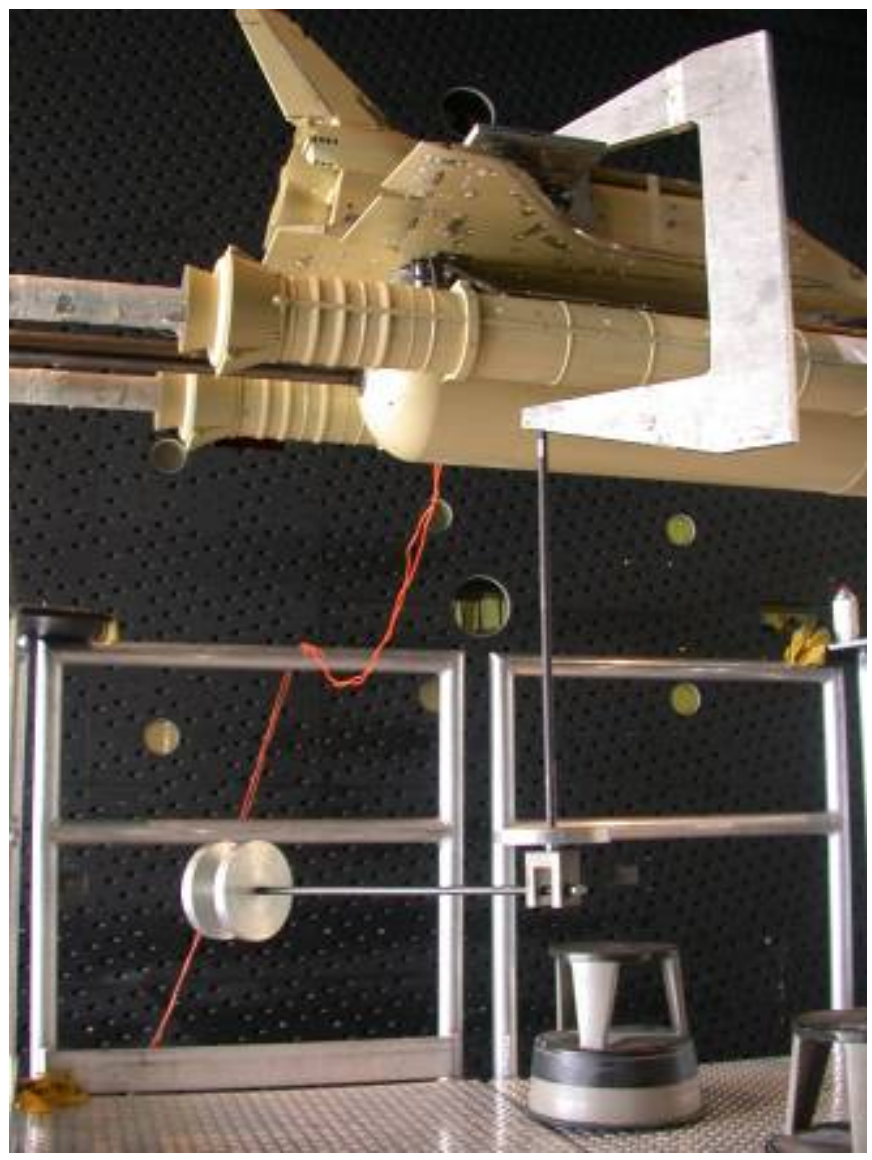

Figure 5. Wind tunnel checkloads. and a good understanding of where the government facilities were with respect to the capability began to emerge, the team began to reach out to industry to try to evaluate and compare with the broader scope of industry utilization.

Two different avenues were used to try to gauge the state of force balances in industry, through both site visits and information requests. The team visited two balance technology development contractors: Modern Machine and Tool in Hampton, VA and Triumph Engineering in San Diego, CA. These two companies do the lion's share of outsourced force balance work in the U.S. The team also visited two industry wind tunnels: the Lockheed Martin High Speed Wind Tunnel in Dallas, TX and the Boeing Transonic Wind Tunnel (BTWT) and Commercial Airplane Group in Seattle, WA. These other wind tunnel sites gave the team insight into how other facilities manage their balance inventories and services.

In addition to the site visits, questionnaires were also sent out to all of the major wind tunnel customers at AEDC and NASA facilities. The questionnaires served a double purpose of both asking for information on the customer's balance experience and possible balance inventories they had on hand and of asking for input on the direction of the team. Whether on a site visit or through an e-mailed questionnaire, a wide variety of topics was touched upon with the goal of learning as much about the current state of force measurement as possible. These topics included all of the following items:

- Design and analysis techniques (type, who does the design: in-house or contract)

- Manufacture (who builds them: in-house or contract)

- Construction (specific material used, method of construction, etc.)

- Gaging and wiring (type, who makes them)

- Moisture proofing (method, material, source of material)

- Compensation and range (thermal, modulus, apparent strain, thermal gradient)

- Desired and achieved accuracy (and method of specifying accuracy)

- Calibration (method, size of matrix, math model, load combinations, increment size, frequency, full or partial, traceability of weights, time required, tare load removal technique, etc.) 
- Calibration instrumentation (type, accuracy, etc.)

- Tunnel instrumentation (type, accuracy, etc.)

- Interfaces between balance and metric and nonmetric ends

- Any other areas respondents considered important to the successful use of balances

The surveys and site visits allowed for valuable information gathering opportunities and a complete view to assess the present state of balance technology. The team assembled, correlated, and sorted all the gathered data to try to draw conclusions on present practices and future direction, including specific problem areas where the community should be putting concerted effort to make improvements. This led to the team findings and recommendations, with the ultimate goal, of course, of benefiting the entire community of balance users.

\section{Issues and Findings}

The findings of the team with respect to the current state of balances around the nation showed the technology was a key capability that was becoming more and more critical with requirements for increasingly precise and accurate measurements. But even more important than the instruments themselves are the people and infrastructure that must be available to make the balances work. An instrument does no good without the data systems to report the measurement, the apparatus to calibrate it, and the people to make it work and integrate it into a test article. A global list of these requirements is shown in Fig. 6, followed by some of the key findings of the team.

\section{Requirements}

$\begin{array}{cl}\text { National Capability } & \text { Support Contracts } \\ \text { - Assets } & - \text { Engineering } \\ \text { - Balance Hardware } & \text { - Design } \\ \text { - Calibration Systems } & \text { - Fabrication } \\ \text { - Data systems } & - \text { Strain-gaging } \\ \text { - Operational } & - \text { Calibration } \\ \text { Enviranments } & - \text { Technology Development } \\ \text { - Competency } & \text { - Recapitalization } \\ \text { - Engineering } & - \text { Standardization } \\ \text { - Calibration } & - \text { Databaseadministration } \\ \text { - Data systems } & - \text { Troubleshooting } \\ \text { - Test article integration } & \\ \text { - Troubleshooting } & \end{array}$

Figure 6. Comprehensive list of requirements examined by the team.

Strain-gage balance technology is a key aeronautical capability addressed by the National Aeronautics R\&D Policy

- "We will dedicate ourselves to the mastery and intellectual stewardship of the core competencies of Aeronautics," and "key aeronautical capabilities"

- Capability in this technology is not one that NASA can readily purchase - the instruments are complex and require an extensive experience-based competency

Balance technology is becoming more critical in the aeronautics test process, not less critical

- Sufficiently accurate simulation fidelity is highly dependent on force/moment metrology

- Current technology is being pushed to the limit to meet the precision/accuracy demands of test customers

- Maintenance of the balance inventory and related infrastructure is essential to operational readiness

- Calibration costs are high and time-consuming, but crucial - efficiencies could be gained and uncertainty levels lowered with investments and standardization 
Although balance systems are complex and vital, they are not the discriminator in the wind tunnel testing business - people are

- Effective wind tunnel testing requires owners to control the key processes, including metrology

- AEDC, Lockheed Martin, and Boeing each retain an in-house competency in straingage balances

- Wind tunnel test customers expect this competency to reside at or within close reach of the test facilities

While the technology was becoming more critical, the team also saw that the current state of the hardware was deteriorating, with most inventories showing signs of extreme age and a majority of balances having been designed and fabricated in the 1960s and 1970s. Many existing balances were becoming mechanically worn out, and many more were not able to meet the reliability and accuracy requirements demanded by customers, including test-to-test repeatability requirements.

The initial findings of the team also confirmed many of the concerns of the ATP about the state of NASA's strain-gage balance capabilities. While AEDC and industry wind tunnels at Boeing and Lockheed Martin each had a core group of balance technologists onsite to support wind tunnel testing, NASA had lost almost its entire balance workforce and was forced to rely on a decreasing cadre of offsite contractors and "favors" from the remaining two or three NASA balance experts who now support other NASA mission areas. Those issues are described in the next group of findings:

$>$ First and foremost, NASA's capability to use strain-gage balances in wind tunnel testing has severely eroded over the past few years

- The number of full-time equivalents (FTE) at LaRC has dropped by $80 \%$ in about 7 years, while the number of contractor personnel dropped by more than $50 \%$.

- To go along with the loss of personnel, investment in balance hardware systems dropped by over $70 \%$ and was typically only done when a specific test program needed a specific capability

- Th workforce was reduced because of attrition and relocation, leaving much of the required e troubleshooting work up to "informal networks" of people solving problems whenever they could

- The ability of the facility personnel to handle novel testing applications is basically gone

$>$ Congruent with NASA's capability losses is the limited and eroding capability of contractors

- As a wind tunnel-specific application, there is a very small market for balance services from a few select government and industry facilities around the nation

- Spending on balances and related technologies for these test facilities followed the same downward trend as for maintenance and recapitalization spending

- As a result NASA increasingly relied on outsourcing for this technology area, then radically reduced spending on it

$>$ Several forces have combined to exacerbate NASA's strain-gage balance weaknesses

- Age of the workforce, inventory, and infrastructure

- Reduced operations and maintenance budgets

- Underutilization of assets, limiting the income available to maintain their condition and capability

- The geographic decentralization of the three distinct test centers of ARC, GRC, and LaRC, leaving each center "on their own" for balance capability

The impacts of these findings are wide and varied. All of the wind tunnel facilities visited were, of course, "making do" with what they had. Aging equipment, as is true anywhere, leads to decreased availability and increasing maintenance costs. For balances, this led to such things as low-quality taper gages for model fabrication and fit checks, time-consuming and labor-intensive weight hanging for checkloads, and limitations in calibration accuracy because of calibration hardware designs. Poor inventory choices led to the need to borrow balances from other facilities or to require customers to supply their own instruments. Even then, there was no formal borrowing 
mechanism between facilities even within NASA, much less with other operations around the country. Ultimately, the biggest impact is the one that is most difficult to measure: the increase in risk to aerospace programs.

\section{Recommendations and the Way Forward}

With the findings of the team complete, several recommendations were formulated and briefed to upper management within NASA, including ATP, SCAP, ARMD, PA\&E, and Air Force management at AEDC. The team recommended that there be central management of balance design, fabrication, calibration and infrastructure control inside NASA along with re-establishment of necessary expertise to ensure a minimum balance competency at each center for their specific needs. Immediate attention needed to be paid to recapitalization of the balance inventory and related infrastructure, including calibration systems and data acquisition systems. Another strong recommendation was for NASA and the Air Force to partner and collaborate as much as possible with regards to capital investments and technology development. With this in mind, a few broad action plans were laid out:

- NASA LaRC would become the lead integrator for strain-gage balance technology for all NASA Centers

- The ATP and the Centers would fund NASA and contractor labor for a new balance organization along with projects to enhance balance capability

- Initial focus of the new group would be recapitalization of the balance inventory and infrastructure

- That group would leverage AEDC capability and expertise with inter-government collaboration efforts

- A procurement strategy would be developed to provide access to balance service providers and allow use by all NASA centers as well as AEDC

The briefing regarding recommendations basically concluded the team's charter, but it is just the beginning of the work that needs to be done. A NASA project has been created to begin to implement these recommendations. The project goal is to establish a national force measurement technology capability to support aeronautics test requirements for NASA, AEDC, and the U.S. The initial emphasis will be on wind tunnel strain-gage balances. The approach to achieving this goal is to increase critical skilled knowledge, to advance technology in existing and new balances and related systems, and to demonstrate integrated systems performance using these technologies. This will be done by addressing weaknesses within specific balance technology areas through investments in staff, recapitalization, procurement strategy, and centralization of the competency. With the thought that centralization of key process control activities (engineering, test technology development, standardization and investments) is a logical first step toward restoring NASA's strain-gage balance capability and contract effectiveness, the project office will be set up at NASA Langley in Hampton, VA. Though the office will be located there, wind tunnel owners at each respective site must continue to manage competency risks by dedicating onsite engineers and technicians as technology integrators and outsourcing to prequalified firms, as required, in order to manage demand surges and maintain their balance system infrastructure.

The National Force Measurement Technology Capability (NFMTC) project office will be organized as shown in Fig. 7. Project implementation includes representation from NASA Ames Research Center, NASA Glenn Research Center, NASA Langley Research Center, and the U.S. Air Force's Arnold Engineering and Development Center. Problem solving will be accomplished through the Project Team with help from the Advisory Team as needed. The Advisory Team, comprised of the Center ATP Program Manager, the ATP Points-of-Contact (POC), and key representatives from NASA and Department of Defense (DoD) Programs, will provide input to the NFMTC Office on its planning and implementation plans from a customer perspective. This input is advisory-only and not mandated to the office. Technical representatives from each of the centers will participate in all aspects of project planning and will provide onsite technical support at each of the locations.

While concentrated on balances with a capabilities-based activity, the project will touch a wide swath of topics and issues to meet its goals. These include:

- Force measurement design, strain-gaging, calibration, and fabrication

- Materials, sensors, stress analyses, fracture mechanics, and fatigue analyses

- Balances, calibration systems, inspection techniques

- Statistical engineering (Design of Experiments (DOE), Response Surface Methodology RSM), uncertainty analyses, statistical quality control

- Standards and training documents

- Trained personnel in force measurement technology 


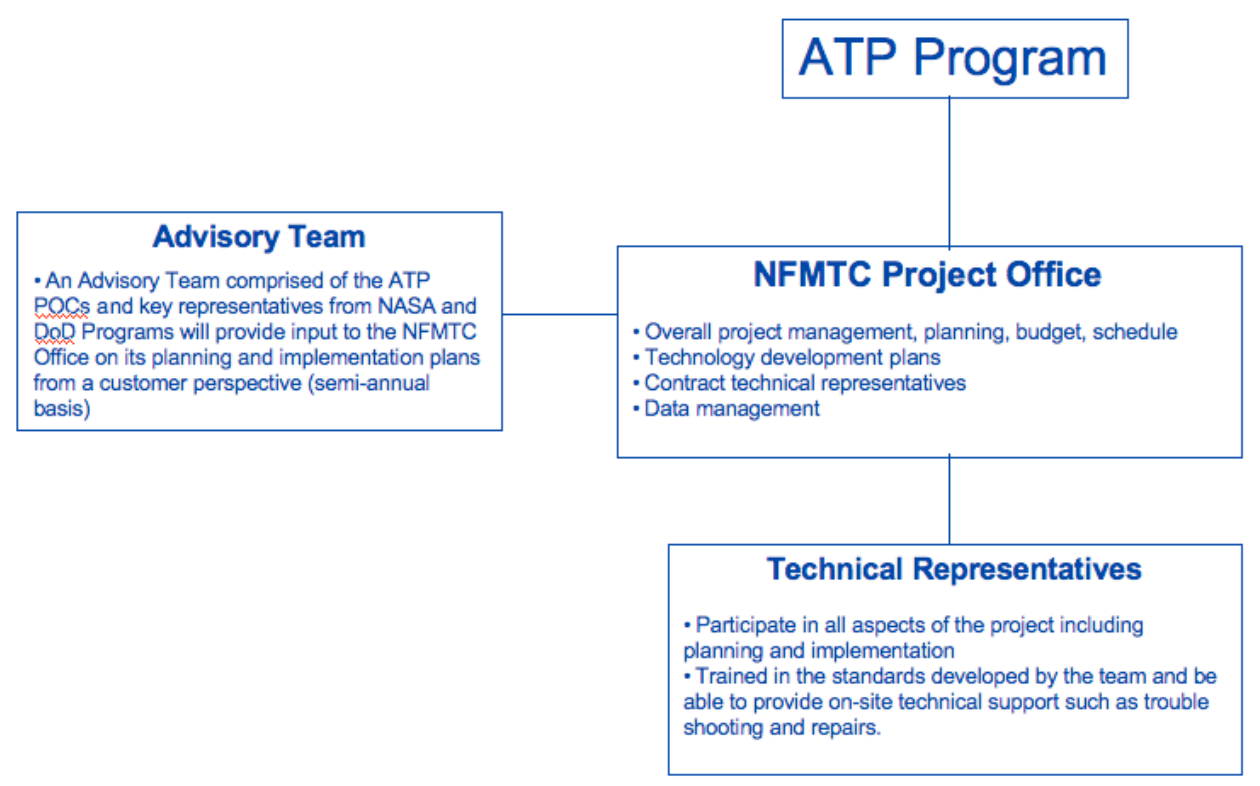

Figure 7. Force measurement project organization.

The project objectives and respective approaches are described below:

Objective 1: Re-capitalize NASA's strain-gage balance inventory.

Approach: Develop a national database, balance readiness evaluation criteria, and a prioritized list of balances to add/modify in order to increase readiness for use inventory

Objective 2: Develop a best practices guide for NASA strain-gage balance technology.

Approach: Assemble best practices in all areas of balance development from each Center, AIAA, industry, and academia.

Objective 3: Improve balance calibration capability.

Approach: Assess current techniques and provide recommended improvements and practices through quantitative analyses.

Objective 4: Establish and maintain staffing to sustain capability.

Approach: Establish technical staff needed for the organization and develop training plans for each technical discipline.

Objective 5: Reduce contract task "turn-on” time.

Approach: Coordinate contract administration and streamline process to access all major balance vendors.

Objective 6: Increase research and development investment.

Approach: Develop coordinated research development plan.

Objective 7: Collaborate with AEDC on force measurement activities.

Approach: Develop a Memorandum of Agreement (MOA) to coordinate all activities within this implementation plan with AEDC through either concurrence or shared responsibilities.

Objective 8: Collaborate with industry and academia on force measurement activities.

Approach: Develop activities to collaborate with industry and academia.

Objective 9: Be recognized as the force measurement consultants for NASA.

Approach: Develop informational brochure and contact lists within the NASA force measurement user community.

Objective 10: Establish a business management strategy

Approach: Develop a business management strategy to sustain force measurement capabilities.

Although the project's official kickoff was not until the first of October with the beginning of fiscal year 2009, over \$1M was allocated during FY2008 to begin some efforts and to lay the groundwork for the road ahead. To give an idea of the range of topics involved, a complete list of items either begun with the initial funding or on the table to be executed during FY09 is shown in Fig. 8. 


\begin{tabular}{|c|c|c|}
\hline Item & Category & Description \\
\hline Weight basket & Infrastructure & Design and develop new generation weight basket for manual loadings \\
\hline $\begin{array}{l}\text { Primary standards } \\
\text { calibrated }\end{array}$ & Infrastructure & $\begin{array}{l}\text { Calibrate the primary mass standards at the National Institute of Standards } \\
\text { and Technology (NIST) according to NIST recommendations }\end{array}$ \\
\hline Weight certification & Infrastructure & $\begin{array}{l}\text { Update balance calibration weight certifications. Also, update inventory } \\
\text { control measures and recall system. }\end{array}$ \\
\hline BALFIT & $\begin{array}{c}\text { Infrastructure and } \\
\text { development }\end{array}$ & Continue development of BALFIT software tool and evaluate \\
\hline HiCAP balance evaluation & Development & $\begin{array}{c}\text { Evaluate new Triumph balance for capability, accuracy, temperature } \\
\text { compensation, and stiffness }\end{array}$ \\
\hline AEDC collaboration & $\begin{array}{c}\text { Infrastructure and } \\
\text { development }\end{array}$ & Collaborate with AEDC on selected projects \\
\hline GRC load cart & Infrastructure & $\begin{array}{l}\text { Develop a load cart for applying check loads to balances in the GRC } 10 \times 10 \\
\text { or } 8 \times 6 \text { wind tunnels }\end{array}$ \\
\hline $\begin{array}{l}\text { Gage and calibrate NTF } \\
\text { balances }\end{array}$ & Infrastructure & Gage and calibrate selected National Transonic Facility (NTF) balances \\
\hline Balance storage cabinets & Infrastructure & Updated lockable storage cabinets for all balances at LaRC \\
\hline Balance analysis software & Infrastructure & Update the balance calibration analysis software used at LaRC \\
\hline $\begin{array}{c}\text { Calibration DAS } \\
\text { computers and SW } \\
\text { upgrade }\end{array}$ & Infrastructure & Procure new DAS computers and upgrade SW for newest versions. \\
\hline $\begin{array}{l}\text { Update finite-element } \\
\text { analysis for selected } \\
\text { balances }\end{array}$ & Infrastructure & $\begin{array}{l}\text { Perform finite-element analysis (FEA) on selected balances to update } \\
\text { operational capabilities }\end{array}$ \\
\hline $\begin{array}{c}\text { Temperature } \\
\text { compensation study for } \\
\text { non-cryo balances }\end{array}$ & Development & $\begin{array}{c}\text { Perform temperature compensation studies on unitary balances. Utilizing } \\
\text { cryogenic balance developed techniques. }\end{array}$ \\
\hline $\begin{array}{l}\text { New bearings for single } \\
\text { vector system }\end{array}$ & Infrastructure & $\begin{array}{l}\text { Procure and install new bearings for the Single Vector Balance Calibration } \\
\text { System }\end{array}$ \\
\hline Calibration system study & Development & Perform calibrations on selected systems to evaluate capabilities \\
\hline Balance database & Infrastructure & $\begin{array}{l}\text { Update and improve the balance database with additional search } \\
\text { capabilities }\end{array}$ \\
\hline $\begin{array}{l}\text { LaRC Balance Calibration } \\
\text { Laboratory }\end{array}$ & Infrastructure & Relocate and upgrade the LaRC balance calibration laboratory. \\
\hline
\end{tabular}

Figure 8. Project activities currently underway.

Much work remains to be done, but the team that was brought together to research the current state of the nation's force measurement capabilities has completed its job. Thanks to that team's effort, the activities in Fig. 8 have begun, collaboration meetings are being held, and interest has been renewed for a vital technology that is essential to wind tunnel testing and, ultimately, America’s aerospace advantage.

\section{Acknowledgments}

The authors would like to thank the personnel at each of the sites that were visited for being gracious hosts and answering our many questions. Special thanks to Naresh Patel at Modern Machine in Hampton, VA; Tim Fennel at Lockheed Martin's High Speed Wind Tunnel in Dallas, TX; Dennis Booth at Triumph Aerospace in San Diego, CA; Henry Bennett at the Boeing Transonic Wind Tunnel in Seattle, WA; and Lew Scherer at Northrop Grumman in El Segundo, CA.

\section{References}

${ }^{1}$ AIAA Recommended Practices for Calibration and Use of Internal Strain-Gage Balances with Application to Wind Tunnel Testing, AIAAR-091-2003e 